\title{
Adenosine 5'-monophosphate in asthma: gas exchange and sputum cellular responses
}

\author{
H.A. Manrique, F.P. Gómez, P.A. Muñoz, A.M. Peña, J.A. Barberà, \\ J. Roca and R. Rodríguez-Roisin
}

ABSTRACT: Adenosine 5'-monophosphate (AMP) bronchoprovocation reproduces the lung function abnormalities that occur spontaneously during acute asthma and detects peripheral airway inflammation better than direct bronchoconstrictive agents. Pulmonary gas exchange disturbances may reflect changes in small airways related to airway inflammation rather than bronchoconstriction alone.

The present authors investigated whether AMP induced a greater imbalance in the ventilation/ perfusion ratio than methacholine ( $\mathrm{MCh}$ ), at an equivalent degree of bronchoconstriction, with and without salbutamol pre-medication. In total, 36 asthmatics were studied in three randomised, doubleblind, crossover studies: 1) before and after AMP or MCh; 2) before and 30 min after salbutamol or placebo, followed by AMP; or 3 ) MCh challenge. Sputum was collected before and $4 \mathrm{~h}$ post-challenge.

Compared with MCh, AMP provoked similar pulmonary gas exchange abnormalities at an equivalent degree of intense bronchoconstriction (forced expiratory volume in one second decrease of $28-44 \%$ ). While salbutamol blocked AMP- or MCh-induced bronchoconstriction, arterial oxygen tension $\left(\mathrm{Pa}, \mathrm{O}_{2}\right)$ and alveolar-arterial oxygen tension difference $\left(\mathrm{PA}-\mathrm{a}, \mathrm{O}_{2}\right)$ disturbances induced by $\mathrm{AMP}$ and $\mathrm{MCh}$ were only partially blocked $\left(\mathrm{Pa}_{1} \mathrm{O}_{2}\right.$ by 46 and $42 \%$, respectively; $\mathrm{PA}-\mathrm{a}, \mathrm{O}_{2}$ by 58 and $57 \%$, respectively). Compared with $\mathrm{MCh}, \mathrm{AMP}$ increased the percentage of neutrophils (mean $\pm \mathrm{SE}$ increased from $28 \pm 4 \%$ to $38 \pm 4 \%$ ), but this increase did not occur after salbutamol pre-treatment.

Both adenosine 5'-monophosphate and methacholine induced similar peripheral airway dysfunction. The fully inhibited adenosine 5'-monophosphate-induced neutrophilia with residua hypoxaemia observed after salbutamol treatment is probably related to $\beta_{2}$-agonists acting on both bronchial and pulmonary circulation.

KEYWORDS: Direct and indirect bronchial challenges, induced sputum, multiple inert gas elimination technique, pulmonary gas exchange, short-acting bronchodilators

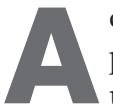
denosine $5^{\prime}$-monophosphate (AMP) is a potent pharmacological agent increasingly used in indirect bronchial challenge tests in patients with asthma. Once inhaled, AMP is rapidly converted to adenosine by the enzyme $5^{\prime}$ nucleotidase. Adenosine is a natural signalling nucleoside and mediator of airway inflammation that induces bronchoconstriction, most likely via the release of inflammatory mediators from mast cells. However, it has also been postulated that adenosine modulates the function of many other cells involved in bronchial hyperresponsiveness and inflammation, such as neutrophils, eosinophils, lymphocytes and macrophages [1]. Moreover, it is suggested that AMP induces bronchoconstriction through the activation of inflammatory mechanisms at the level of the bronchial surface and also through local or central neuronal reflexes [1]. Bronchial challenges with direct agents, such as methacholine $(\mathrm{MCh})$, assess the response to the agent acting directly on receptors while causing airway smooth muscle contraction; in contrast, bronchial challenges with indirect agents, such as AMP, assess the responses to endogenously released substances from resident inflammatory cells, hence reflecting the presence and severity of airway inflammation [2]. Additionally, the provocative concentration (PC) causing a $20 \%$ fall in forced expiratory volume in one second (FEV1) for AMP (PC20 AMP) is more closely associated with airway inflammation in asthma than is PC20 MCh [3], suggesting that PC20 AMP is more sensitive to airway inflammation since it shows a greater response to corticosteroids than does PC20 MCh [4].
AFFILIATION

Servei de Pneumologia (Institut del

Tòrax), Hospital Clínic, Institut

d'Investigacions Biomédiques Augus

Pi i Sunyer (IDIBAPS), Ciber

Enfermedades Respiratorias,

Universitat de Barcelona, Barcelona Spain.

CORRESPONDENCE

R. Rodríguez-Roisin

Servei de Pneumologia

Hospital Clínic

Villarroel 170

08036-Barcelona

Spain

Fax: 34932275404

E-mail: rororo@clinic.ub.es

Received:

September 042007

Accepted after revision:

February 042008

\section{SUPPORT STATEMENT}

Supported by the Fondo de

Investigación Sanitaria, grant FIS 05/ 0208 (Madrid, Spain); the CibeRes, grant CB06/06; the Generalitat de Catalunya, grant 2005SGR-00822 the Sociedad Española de Neumología y Cirugía Torácica and grant SEPAR 2004 (all Barcelona, Spain). H.A. Manrique was supported by a European Respiratory SocietySEPAR 2005 Long-Term Research Fellowship (No. 182). R. RodríguezRoisin holds a career scientist award (2001-2007) from the Generalitat de Catalunya.

STATEMENT OF INTEREST Statements of interest for $\mathrm{R}$. Rodríguez-Roisin and the study itsel can be found at

www.erj.ersjournals.com/misc/ statements.shtml 
The hypothesis of the present study was that bronchial challenge with AMP in patients with mild asthma, in addition to provoking bronchoconstriction in larger airways, would orchestrate inflammatory events and peripheral airway dysfunction, predominantly resulting in pulmonary gas exchange disturbances. Compared with MCh, bronchial challenge with AMP would more closely reproduce the gas exchange abnormalities that occur spontaneously during acute severe asthma.

Previous studies in patients with asthma under different clinical conditions have consistently shown compelling evidence of a poor correlation between the behaviour of reduced maximal expiratory airflow rates and pulmonary gas exchange abnormalities, namely arterial hypoxaemia and its major intrapulmonary determinant, ventilation/perfusion ratio $\left(V^{\prime} / Q^{\prime}\right)$ imbalance $[5,6]$. Conceivably, these findings concur with the hypothesis that decreased spirometric indices reflect reduction of airway calibre in larger and medium-sized bronchi, whereas pulmonary gas exchange disturbances relate predominantly to structural changes in distal small airways, which could be related more to airway inflammation than to bronchoconstriction alone [6]. Notwithstanding, a cause-and-effect relationship will be very difficult to establish in humans. Salbutamol, an inhaled shortacting $\beta_{2}$-adrenergic agonist, inhibits platelet-activating factor (PAF)- and leukotriene (LT) $\mathrm{D}_{4}$-induced increases in airway resistance, sputum and peripheral blood cell abnormalities and gas exchange defects in asthmatics [7-9]. The current authors postulated that these effects of salbutamol could be related to inhibition of capillary endothelial constriction in the bronchial microcirculation [10], without necessarily reflecting its potent relaxant effect on airway smooth muscle.

The first aim of the present study was to investigate whether AMP bronchoprovocation in patients with asthma could induce more $V^{\prime} / Q^{\prime}$ imbalance, as a marker of predominantly peripheral airway inflammation, than $\mathrm{MCh}$ challenge, while provoking similarly intense bronchoconstriction. A secondary end-point was to assess whether salbutamol could inhibit AMP-induced bronchoconstriction and arterial oxygenation defects, while modulating the airway inflammatory cellular response. To date, no data are available in the literature regarding the pulmonary gas exchange response to AMP challenge in asthma.

\section{METHODS}

\section{Patients}

In total, 36 nonsmoking patients, of whom 17 were female, were included in the present study. They had stable intermittent asthma, a mean \pm SE age of $26 \pm 1$ yrs and FEV1 of $91 \pm 4 \%$ predicted. For inclusion, patients were required to have an FEV1 $>70 \%$ pred and $>1.5 \mathrm{~L}$, and a decrease in FEV1 $>20 \%$ from baseline after a standardised AMP or MCh bronchial challenge. All patients were on rescue therapy with a short-acting inhaled $\beta_{2}$-agonist, and four were using inhaled corticosteroids: in study 1 , one patient was taking $800 \mu \mathrm{g} \cdot \mathrm{day}^{-1}$ budesonide and two patients $640 / 18 \mu \mathrm{g} \cdot \mathrm{day}^{-1}$ budesonide/ formoterol; and in study 2 one patient was taking 640/ $18 \mu \mathrm{g} \cdot$ day $^{-1}$ budesonide/formoterol. No patients had taken systemic glucocorticosteroids in the previous 3 months. The study was approved by the Ethics Committee of Hospital Clínic (Barcelona, Spain; registration no. 02-0239 from the Agencia Española del Medicamento) and all the patients gave informed written consent.

\section{Design}

Three sequential studies, with 12 patients in each, were designed in a randomised, double-blind, crossover manner: first to examine the effects of AMP and MCh on airway calibre, gas exchange and airway inflammation (study 1); and secondly to analyse the role of pre-treatment with salbutamol in influencing AMP (study 2) and MCh (study 3) bronchial challenge.

Study 1

On the first visit, clinical evaluation, spirometry and $\mathrm{MCh}$ bronchial challenge were performed. One week later (second visit), induced sputum was obtained for a baseline assessment. On the third visit, patients were randomised to AMP or MCh challenge, and on the fourth visit, 1 week later, they were assigned to the alternative agent. Dose-response challenges were performed until a fall of $\geqslant 30 \%$ in FEV1 from baseline was attained. All sets of measurements, including the multiple inert gas elimination technique (MIGET) and respiratory arterial blood gases, were performed before (at baseline) and 5, 15 and $45 \mathrm{~min}$ after each challenge. Sputum was induced $240 \mathrm{~min}$ after the challenge.

Study 2

On the first visit, clinical evaluation, spirometry and AMP bronchial challenge were performed. On the second visit, induced sputum was obtained for a baseline assessment. On the third and fourth visits (1 week apart), patients were challenged with AMP, after randomisation to inhaled salbutamol $(400 \mu \mathrm{g})$ or placebo (lactose) pre-treatment. The same measurements as in study 1, apart from MIGET, were performed at baseline (B0), $30 \mathrm{~min}$ after salbutamol or placebo administration (B1) and 5, 15 and 45 min after AMP challenge. Sputum was induced $240 \mathrm{~min}$ after the challenge.

Study 3

This study followed the same design as study 2, but used MCh instead of AMP.

\section{Measurements}

FEV1, respiratory system resistance $(R r s)$, arterial oxygen tension $\left(\mathrm{Pa}, \mathrm{O}_{2}\right)$, arterial carbon dioxide tension $\left(\mathrm{Pa}, \mathrm{CO}_{2}\right)$, oxygen uptake $\left(V^{\prime} \mathrm{O}_{2}\right)$, carbon dioxide production and $\mathrm{pH}$ were measured. The alveolar-arterial oxygen tension difference $\left(\mathrm{PA}-\mathrm{a}, \mathrm{O}_{2}\right)$ was calculated according to the alveolar gas equation, using the measured respiratory exchange ratio. In study 1 (AMP or MCh challenge), MIGET was used to estimate the distribution of $V^{\prime} / Q^{\prime}$ ratios without sampling mixed venous inert gases [11]. Cardiac output (QT) was measured by the dye solution technique using a 5-mL bolus of indocyanine green. After ensuring steady-state conditions, a set of duplicate measurements for each variable was obtained at each time-point.

Fresh samples of induced sputum were processed before and $4 \mathrm{~h}$ after each bronchial challenge [12]. Concentrations of interleukin (IL)-8 in studies 1, 2 and 3, and IL-2, IL-4, IL-10 and interferon (IFN)- $\gamma$ in studies 2 and 3 were measured in the sputum supernatant. Paired measurements of induced sputum were completed in studies 1 and 2 (10 patients in each).

\section{Statistical analysis}

Results are expressed as mean \pm SE or mean (95\% confidence interval). The PC25 values for AMP and MCh were derived by linear interpolation from the log-cumulated dose-response curve 
TABLE 1 Patient characteristics and lung function data at baseline for all bronchial challenge visits

\begin{tabular}{|c|c|c|c|c|c|c|}
\hline & \multicolumn{6}{|c|}{ Study } \\
\hline & \multicolumn{2}{|c|}{1} & \multicolumn{2}{|c|}{2 AMP } & \multicolumn{2}{|c|}{$3 \mathrm{MCh}$} \\
\hline Age yrs & \multicolumn{2}{|c|}{$25 \pm 1$} & \multicolumn{2}{|c|}{$26 \pm 1$} & \multicolumn{2}{|c|}{$28 \pm 1$} \\
\hline Sex $M / F n$ & \multicolumn{2}{|c|}{$7 / 5$} & \multicolumn{2}{|c|}{$7 / 5$} & \multicolumn{2}{|c|}{$5 / 7$} \\
\hline \multicolumn{7}{|l|}{ First visit } \\
\hline FEV $1 / F V C$ & \multicolumn{2}{|c|}{$0.80 \pm 0.03$} & \multicolumn{2}{|c|}{$0.78 \pm 0.02$} & \multicolumn{2}{|c|}{$0.77 \pm 0.02$} \\
\hline Rrs $\mathrm{cmH}_{2} \mathrm{O} \cdot \mathrm{L}^{-1} \cdot \mathrm{s}$ & \multicolumn{2}{|c|}{$4.5 \pm 0.4$} & \multicolumn{2}{|c|}{$4.3 \pm 0.3$} & \multicolumn{2}{|c|}{$3.9 \pm 0.4$} \\
\hline Third or fourth visit & AMP & MCh & Placebo & Salbutamol & Placebo & Salbutamol \\
\hline $\mathrm{FEV}_{1} \mathrm{~L}$ & $3.2 \pm 0.2$ & $3.2 \pm 0.2$ & $3.5 \pm 0.2$ & $3.5 \pm 0.2$ & $3.3 \pm 0.2$ & $3.3 \pm 0.2$ \\
\hline $\operatorname{Rrs} \mathrm{cmH}_{2} \mathrm{O} \cdot \mathrm{L}^{-1} \cdot \mathrm{s}$ & $4.6 \pm 0.3$ & $4.6 \pm 0.4$ & $4.4 \pm 0.4$ & $4.3 \pm 0.3$ & $4.0 \pm 0.4$ & $3.9 \pm 0.4$ \\
\hline QT L.min ${ }^{-1}$ & $5.7 \pm 0.3$ & $5.6 \pm 0.3$ & & & & \\
\hline $\log S D Q$ & $0.47 \pm 0.04$ & $0.44 \pm 0.02$ & & & & \\
\hline $\log$ SDV & $0.48 \pm 0.03$ & $0.45 \pm 0.02$ & & & & \\
\hline DISP R-E* & $3.15 \pm 0.49$ & $2.38 \pm 0.26$ & & & & \\
\hline
\end{tabular}

Data are presented as mean \pm SE, unless otherwise stated. AMP: adenosine 5'-monophosphate; MCh: methacholine; M: male; F: female; FEV1: forced expiratory volume in one second; \% pred: \% predicted; FVC: forced vital capacity; Rrs: respiratory system resistance; $\mathrm{QT}$ : cardiac output; $\mathrm{V}^{\prime} \mathrm{O}_{2}$ : oxygen uptake; $\mathrm{Pa}, \mathrm{O}_{2}$ : arterial oxygen tension;


distribution; DISP R-E*: dispersion of retention minus excretion of inert gases corrected for dead space. $1 \mathrm{mmHg}=0.133 \mathrm{kPa}$.

and geometric means were calculated from log-transformed raw data. In the three studies, the effects of AMP and MCh challenges with or without salbutamol or placebo pre-medication on the different end-point variables were assessed by a two-way repeated ANOVA. In studies 2 and 3, B1 was used as baseline. Whenever there were significant differences, post hoc comparisons at each time point were performed using paired t-tests. In addition, paired t-tests and Pearson's correlation were used when necessary. Statistical significance was set at $\mathrm{p}<0.05$ in all instances.

\section{RESULTS}

\section{Baseline}

Patients had normal FEV1 and arterial blood gases and mild increases in Rrs in all three studies, without significant differences between them (table 1). In study 1, the dispersion of pulmonary blood flow distribution (log SDQ; AMP range (0.33-0.71), MCh $(0.32-0.58)$; normal $\leqslant 0.60)$ and that of alveolar ventilation (log SDV; AMP (0.33-0.67), MCh (0.32-0.58); normal $\leqslant 0.65)$ [13] were narrowly unimodal. An overall index of $V^{\prime} / Q^{\prime}$ heterogeneity, the dispersion of retention minus excretion of inert gases corrected for dead space (DISP R-E*; AMP range (1.03-6.21), MCh (0.91-

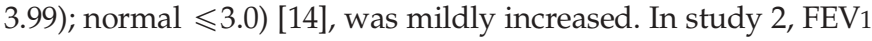
increased from $3.5 \pm 0.2$ to $3.9 \pm 0.2 \mathrm{~L} \quad(\mathrm{p}<0.001)$ and $R r s$ decreased from $4.3 \pm 0.3$ to $3.5 \pm 0.2 \mathrm{cmH}_{2} \mathrm{O} \cdot \mathrm{L}^{-1} \cdot \mathrm{s}(\mathrm{p}<0.02)$ from B0 (before) to B1 (after) in the salbutamol pre-treated patients. Similarly, in study 3, FEV1 increased from $3.3 \pm 0.2$ to $3.7 \pm 0.3 \mathrm{~L}$, while Rrs decreased from $3.9 \pm 0.4$ to $2.9 \pm 0.4 \mathrm{cmH}_{2} \mathrm{O} \cdot \mathrm{L}^{-1} \cdot \mathrm{s}$ ( $p<0.02$ in both cases), from B0 to B1 after pre-treatment with salbutamol. No significant differences in $\mathrm{Pa}_{1} \mathrm{O}_{2}$ and $\mathrm{PA}-\mathrm{a}, \mathrm{O}_{2}$ were observed between measurements carried out before and after salbutamol or placebo pre-treatment (fig. 1).

\section{Study 1: AMP and MCh responses}

When measured $5 \mathrm{~min}$ after AMP challenge with a mean cumulative dose of $6.7 \mathrm{mg}$, there were moderate-to-severe decreases in both FEV1 and $\mathrm{Pa}_{2} \mathrm{O}_{2}$ and increases in both $R \mathrm{rs}$ and $P A-a, \mathrm{O}_{2}$ that did not differ from those shown after bronchoconstriction induced by $\mathrm{MCh}$ with a mean cumulative dose of $0.15 \mathrm{mg}$ (table 2). AMP- and MCh-induced decreases in $\mathrm{Pa}_{\mathrm{a}_{2}}$ were caused by mild-to-moderate $V^{\prime} / Q^{\prime}$ inequalities, as reflected by increases of the same order of magnitude in both $\log$ SDQ and DISP R-E*, whereas log SDV remained unchanged. Overall, $V^{\prime} / Q^{\prime}$ distributions were broadly unimodal. In contrast, $\mathrm{Pa}_{1} \mathrm{CO}_{2}, \mathrm{pH}, V^{\prime} \mathrm{O}_{2}$, minute ventilation, respiratory frequency, mean blood pressure and cardiac frequency remained essentially unchanged after challenge. Compared with MCh challenge, QT increased 5 and 15 min after AMP bronchoconstriction (by 15 and 11\%, respectively; $p<0.05$ for both time points). Apart from QT, all altered variables showed a trend towards recovery by 15 and 45 min after AMP. Both FEV1 and Rrs were mildly abnormal at the end of the study. The residual sum of squares, the best descriptor of the quality of MIGET data, was within the expected limits $(\leqslant 5.0 ; 2.1 \pm 0.3$ and $2.4 \pm 0.4$ for $\mathrm{AMP}$ and MCh, respectively) [13]. By $4 \mathrm{~h}$ after AMP inhalation, sputum neutrophils had increased significantly $(p<0.05$; table 3). Two out of the three patients previously treated with inhaled glucocorticosteroids did not show a distinct neutrophil increase post-AMP challenge; in the third patient, sputum was not obtained. IL-8 showed a tendency to decrease after AMP and $\mathrm{MCh}$ challenges compared with baseline values (table 3). Baseline DISP R-E $E^{*}$ and $\mathrm{Pa}, \mathrm{O}_{2}$ were inversely correlated before AMP challenge $(r=-0.61, p<0.05)$. When measured 5 min after 

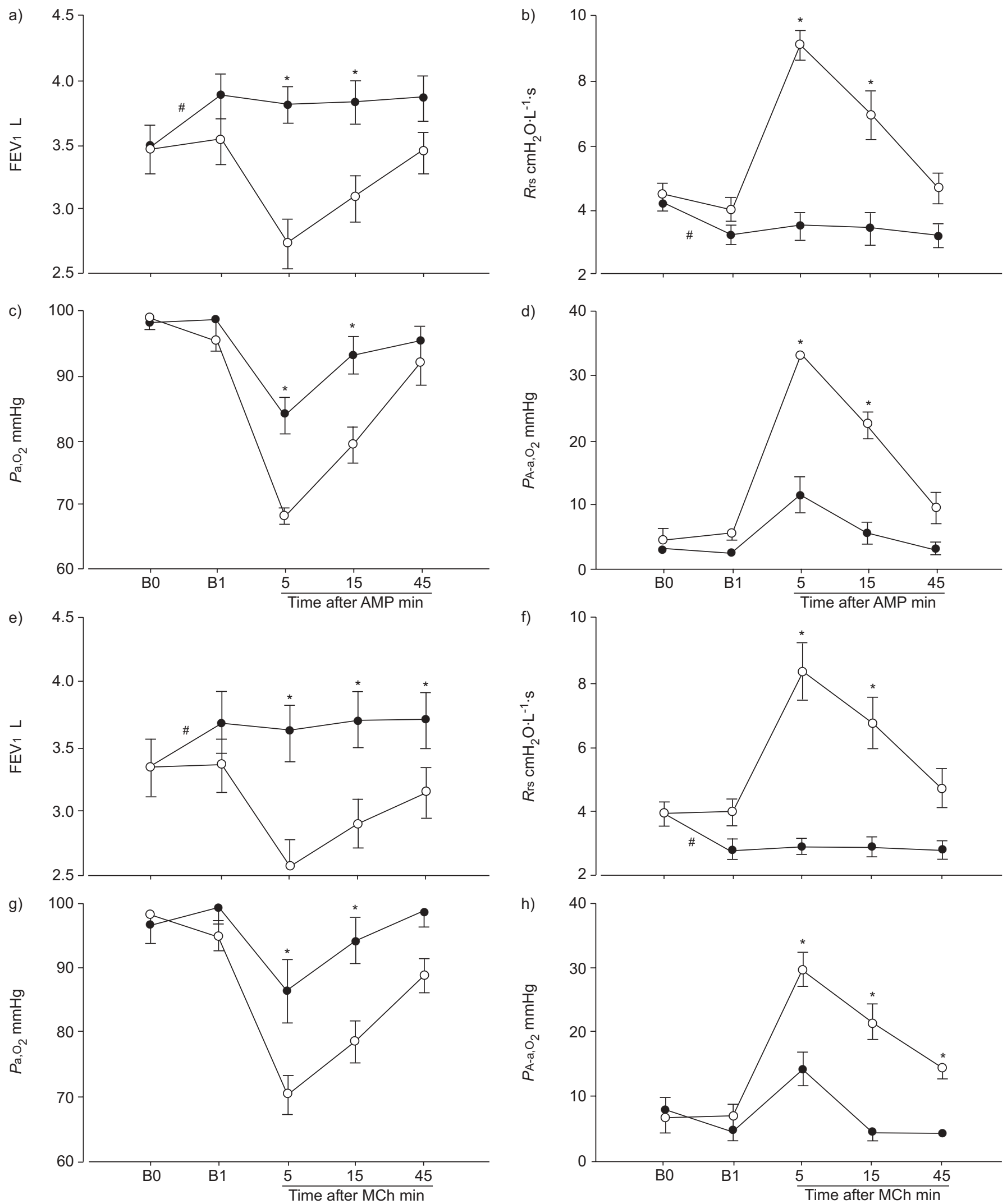

FIGURE 1. Time courses (mean $\pm \mathrm{SE}$ ) for forced expiratory volume in one second (FEV 1 ; a and e), respiratory system resistance (Rrs; b and f), arterial oxygen tension $\left(\mathrm{Pa}_{2} \mathrm{O}_{2} ; \mathrm{C}\right.$ and $\left.\mathrm{g}\right)$ and alveolar-arterial oxygen tension difference $\left(\mathrm{PA}-\mathrm{a}, \mathrm{O}_{2} ; \mathrm{d}\right.$ and h), measured at baseline (B0), 30 min after salbutamol $(\bullet)$ or placebo $(\mathrm{O})$ pre-treatment (B1), and 5, 15 and 45 min after adenosine 5'-monophosphate (AMP; a-d) or methacholine (MCh; e-h) bronchial challenge. *: p<0.05 between salbutamol and placebo \#: $\mathrm{p}<0.02$ between B0 and B1 for salbutamol or placebo. $1 \mathrm{mmHg}=0.133 \mathrm{kPa}$. 


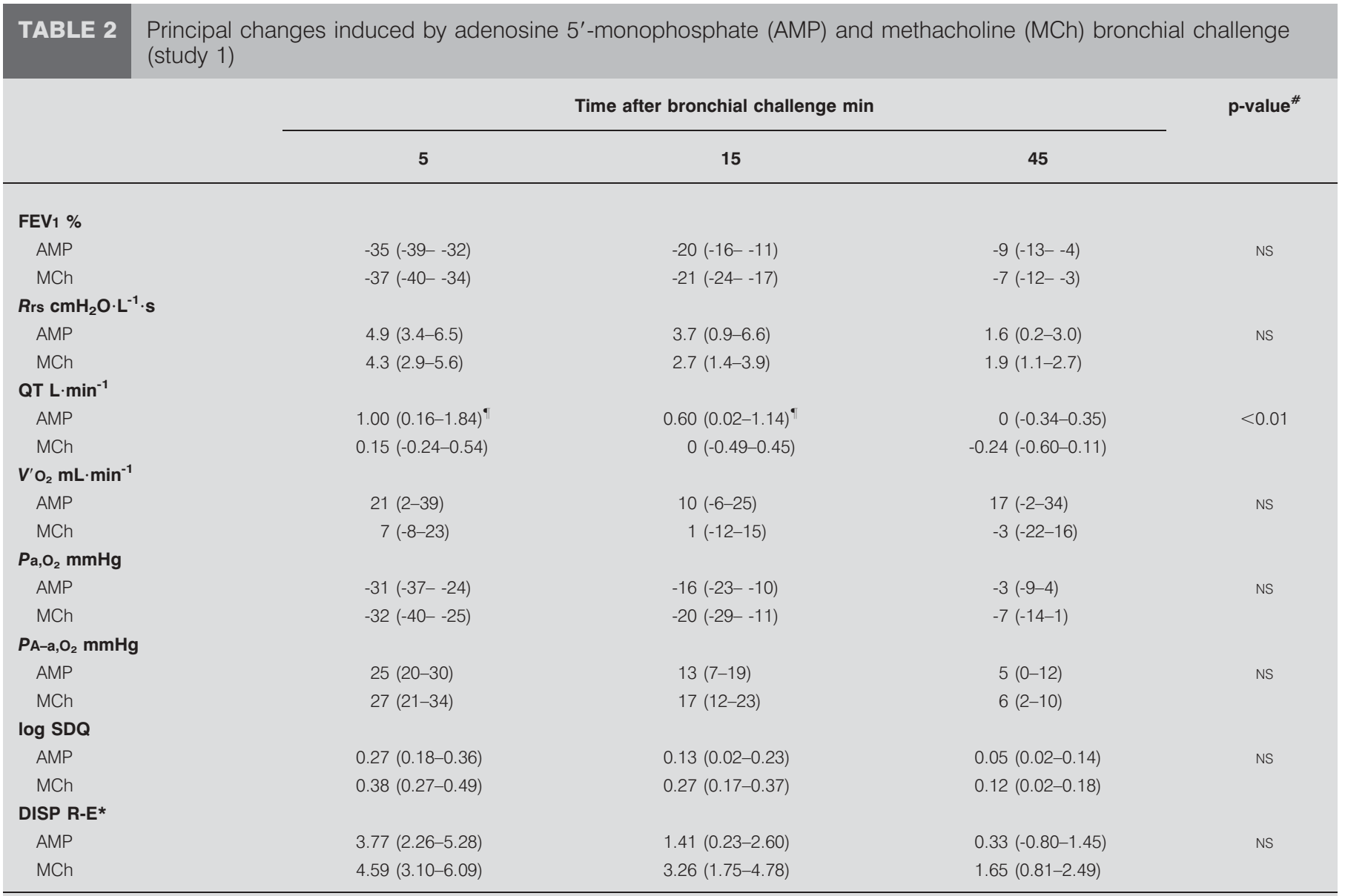

Data are presented as mean differences (95\% confidence interval) from baseline measurements, unless otherwise stated. FEV1: forced expiratory volume in one second; Rrs: respiratory system resistance; $\mathrm{QT}$ : cardiac output; $\mathrm{V}^{\prime} \mathrm{O}_{2}$ : oxygen uptake; $\mathrm{Pa}_{2} \mathrm{O}_{2}$ : arterial oxygen tension; $\mathrm{PA}-\mathrm{a}, \mathrm{O}_{2}$ : alveolar-arterial oxygen tension difference; log SDQ: dispersion

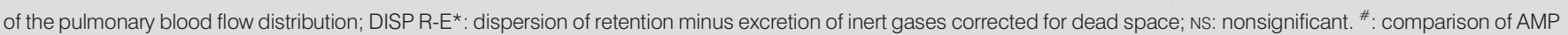
and MCh challenges, using ANOVA two-way repeated measures. ${ }^{\circ} \mathrm{p}<0.05$ for comparisons between AMP and MCh at single time points. $1 \mathrm{mmHg}=0.133 \mathrm{kPa}$.

MCh challenge, $\mathrm{Pa}, \mathrm{O}_{2}$ was inversely correlated with log SDQ $(\mathrm{r}=-0.93, \mathrm{p}<0.01)$ and $\log \operatorname{SDV}(\mathrm{r}=-0.65, \mathrm{p}<0.05)$. There was a positive correlation between $\mathrm{FEV} 1$ and $\mathrm{Pa}, \mathrm{O}_{2}$ changes measured 5,15 and $45 \mathrm{~min}$ after AMP $(\mathrm{r}=0.78, \mathrm{p}<0.01)$ and $\mathrm{MCh}(\mathrm{r}=0.69$, $\mathrm{p}<0.01)$ challenge.

Study 2: AMP challenge and pre-treatment with salbutamol Compared with the placebo, pre-treatment with salbutamol completely blocked the bronchoconstriction induced by AMP (mean cumulative dose $3.6 \mathrm{mg}$ ), such that FEV1 and Rrs remained unchanged after $5 \mathrm{~min}$ (table 4 and fig. 1). In contrast, AMP-induced changes in $\mathrm{Pa}_{1} \mathrm{O}_{2}$ and $\mathrm{PA}-\mathrm{a}, \mathrm{O}_{2}$ were partially blocked (by 46 and 58\%, respectively; table 4 and fig. 1), an inhibitory effect that persisted less intensely for $15 \mathrm{~min}$ ( $\mathrm{p}<0.05$ in each case); by $45 \mathrm{~min}$, both $\mathrm{Pa}, \mathrm{O}_{2}$ and $P \mathrm{~A}-\mathrm{a}, \mathrm{O}_{2}$ showed a tendency to return to baseline levels. In addition, the AMP-induced neutrophilia was significantly blocked by premedication with salbutamol. Compared with baseline, there were no significant differences in the supernatant concentration of IL-8 and IL-2 after AMP challenge in either placebo or salbutamol pre-treated patients (table 3). IL-4, IL-10 and IFN- $\gamma$ supernatant concentrations were not detectable in $>89 \%$ of samples (data not shown). The percentage of neutrophils at baseline inversely correlated with $\mathrm{Pa}_{\mathrm{a}} \mathrm{O}_{2}(\mathrm{r}=-0.84, \mathrm{p}<0.01)$, while IL-2 positively correlated with the percentage of eosinophils $5 \mathrm{~min}$ after AMP challenge $(\mathrm{r}=0.87, \mathrm{p}<0.01)$. There was a close correlation between decreased FEV1 and $\mathrm{Pa}, \mathrm{O}_{2}$ changes 5, 15 and $45 \mathrm{~min}$ after AMP challenge in patients pre-treated with placebo $(r=0.69, p<0.01)$.

Study-3: MCh challenge and pre-treatment with salbutamol As in study 2, when compared with placebo, salbutamol completely inhibited the bronchoconstriction induced by MCh (mean cumulative dose $0.27 \mathrm{mg}$ ) $5 \mathrm{~min}$ after $\mathrm{MCh}$ challenge but only partially blocked $\mathrm{Pa}, \mathrm{O}_{2}$ and $\mathrm{PA}-\mathrm{a}, \mathrm{O}_{2}$ abnormalities (by 42 and $57 \%$, respectively; table 4 and fig. 1 ). These changes persisted for $15 \mathrm{~min}(\mathrm{p}<0.05$ in each case); by $45 \mathrm{~min}$, compared with placebo, $\mathrm{Pa}_{\mathrm{a}} \mathrm{O}_{2}$ and $\mathrm{PA}-\mathrm{a}, \mathrm{O}_{2}$ changes still remained slightly different. No substantial changes were observed in sputum cells after pre-medication with salbutamol or placebo. Overall, IL-4, IL-10 and IFN- $\gamma$ supernatant concentrations were not detectable in $>86 \%$ of samples (data not shown). There was a significant correlation between the time-course of the FEV1 fall (expressed as \% change from baseline) and that of $\mathrm{Pa}_{1} \mathrm{O}_{2} 5,15$ and $45 \mathrm{~min}$ after challenge $(\mathrm{r}=0.70 ; \mathrm{p}<0.01)$. No differences were observed in the four 
TABLE 3 Sputum total cell count and differential cell percentages for each study at baseline and $4 \mathrm{~h}$ after bronchial challenge

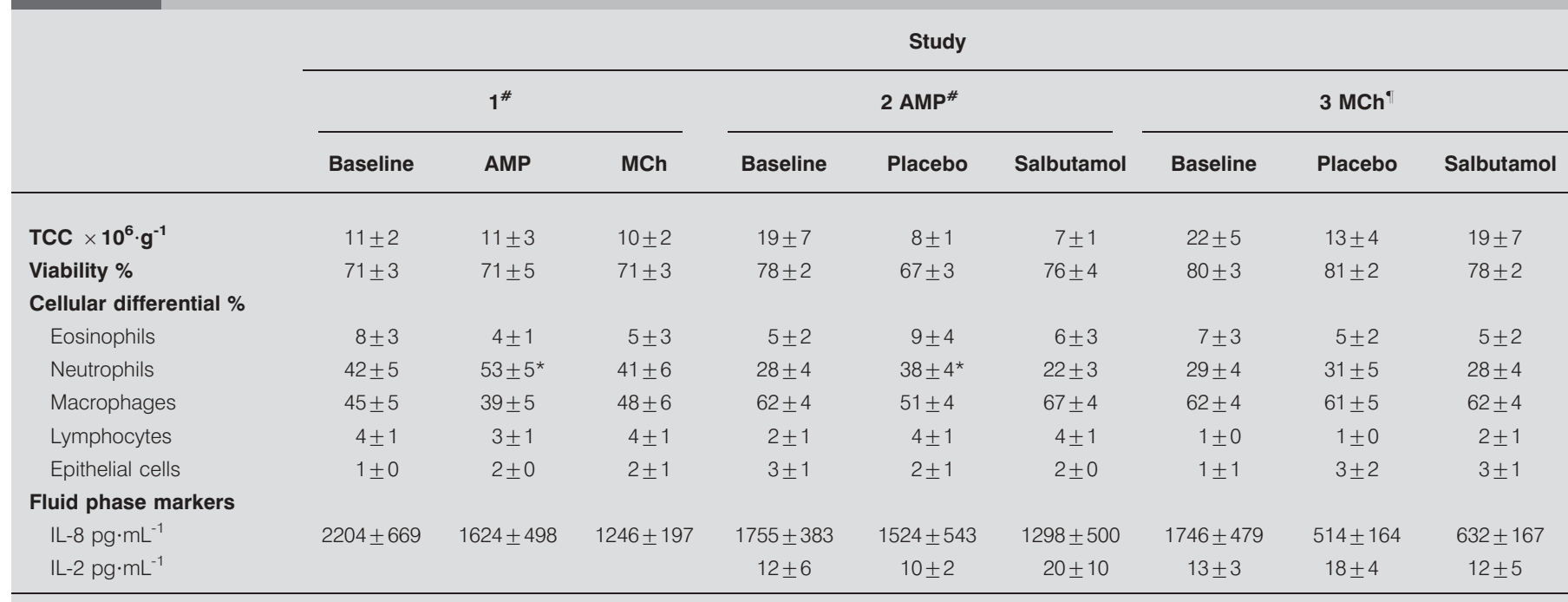

Data are presented as mean \pm SE, unless otherwise stated. AMP: adenosine $5^{\prime}$-monophosphate; MCh: methacholine; TCC: total cell count; IL: interleukin. \#: $\mathrm{n}=10$; $\because: n=12 .{ }^{*}: p<0.05$ compared with baseline.

principal variables (FEV1, Rrs, $\mathrm{Pa}_{\mathrm{a}} \mathrm{O}_{2}$ and $\mathrm{Pa}_{\mathrm{a}} \mathrm{CO}_{2}$ ) between salbutamol and placebo pre-treatments, when AMP (study 2) and MCh (study 3) challenges were compared.

\section{DISCUSSION}

\section{Major findings}

There were three principal novel findings in the present study in patients with stable mild asthma. First, compared with MCh, AMP (in study 1) transiently provoked similar pulmonary gas exchange abnormalities at an equivalent degree of intense bronchoconstriction, essentially characterised by moderate decreases in $\mathrm{Pa}_{1} \mathrm{O}_{2}$ and increases in $\mathrm{PA}-\mathrm{a}, \mathrm{O}_{2}$, due to the development of low $V^{\prime} / Q^{\prime}$ ratio units as assessed by increases in $\log$ SDQ. Similarly, arterial blood gas abnormalities were observed, although slightly less pronounced, when AMP and $\mathrm{MCh}$ bronchoprovocations were randomised to placebo or salbutamol pre-treatment (studies 2 and 3). Secondly, AMP challenge provoked mild sputum neutrophilia, an effect that was completely blocked by salbutamol pre-medication (study 2). Thirdly, pre-treatment with salbutamol completely blocked AMP- and MCh-induced bronchoconstriction but only partially blocked arterial blood gas disturbances (studies 2 and 3).

\section{Pulmonary gas exchange response to AMP and MCh challenge}

The post-challenge pulmonary gas exchange defects resulting in moderate decreases in $\mathrm{Pa}, \mathrm{O}_{2}$ and increases in $\mathrm{PA}-\mathrm{a}, \mathrm{O}_{2}$ due to mild-to-moderate $V^{\prime} / Q^{\prime}$ imbalance did not differ according to bronchoconstrictive agent. However, the simultaneous increase in QT immediately after AMP challenge, probably related to AMP-induced inotropism [15], should have increased mixedvenous oxygen content, hence increasing $\mathrm{Pa}_{2} \mathrm{O}_{2}$, other things being equal [6]. Alternatively, post-AMP increased QT should have facilitated further $V^{\prime} / Q^{\prime}$ worsening, by diverting more blood flow to low $V^{\prime} / Q^{\prime}$ ratio units. The latter changes may have been offset by a simultaneous AMP-induced enhancement of hypoxic pulmonary vasoconstriction, hence reducing the deleterious impact of increased QT on $V^{\prime} / Q^{\prime}$ imbalance.
These post-AMP gas exchange defects are akin to those observed following exposure to different types of direct agents, e.g. allergens [16], MCh and histamine [17], and $\mathrm{LTD}_{4}$ [18], or indirect agents, e.g. PAF [19]. However, the AMP-induced gas exchange abnormalities differed from those provoked by both exercise and mannitol bronchoprovocation, which affected not only the log SDQ but also the log SDV [20]. Overall, these bronchial challenge-induced gas exchange findings indicate that all direct and most indirect agents provoke similar bronchoconstrictive responses, irrespective of the initial biochemical and/or cellular pathway [21]. Therefore, the present findings refute the hypothesis that AMP could produce more widespread airway inflammation, thus more $V^{\prime} / Q^{\prime}$ imbalance, than $\mathrm{MCh}$. Instead, AMP-induced gas exchange abnormalities point to the view that the mechanisms of bronchial responsiveness are similarly heterogeneous in their topographical basis and distributed in both central and peripheral airways, a finding already observed after $\mathrm{MCh}$ and histamine challenge in mild asthma $[17,18]$.

\section{Induced sputum findings}

There was a significant late increase in neutrophils in induced sputum after AMP inhalation, at variance with the predominant eosinophilia previously shown after AMP challenge [22, 23]. This neutrophilia is, however, consistent with previous data observed in persistent asthma [24] and in a mouse AMP model [25]. Therefore, the current findings provide the first evidence that AMP inhalation has a late effect on airway neutrophil migration in asthmatics. There is evidence that AMP challenge may provoke cellular chemoattraction within the airways through the release of a variety of inflammatory mediators from lung mast cells, namely $\mathrm{LTB}_{4}, \mathrm{IL}-5, \mathrm{IL}-8$ and tumour necrosis factor- $\alpha$, all chemoattractants for neutrophils $[12,26]$. The percentage of neutrophils did not correlate with IL-8 in the present study, possibly because the latter measurements were not sufficiently sensitive or other unmeasured mediators and/or receptors could have been involved. 
TABLE 4 Changes induced by adenosine $5^{\prime}$-monophosphate (AMP) and methacholine (MCh) bronchial challenge, with placebo and salbutamol pre-medication

Time after bronchial challenge min

p-value

15

45

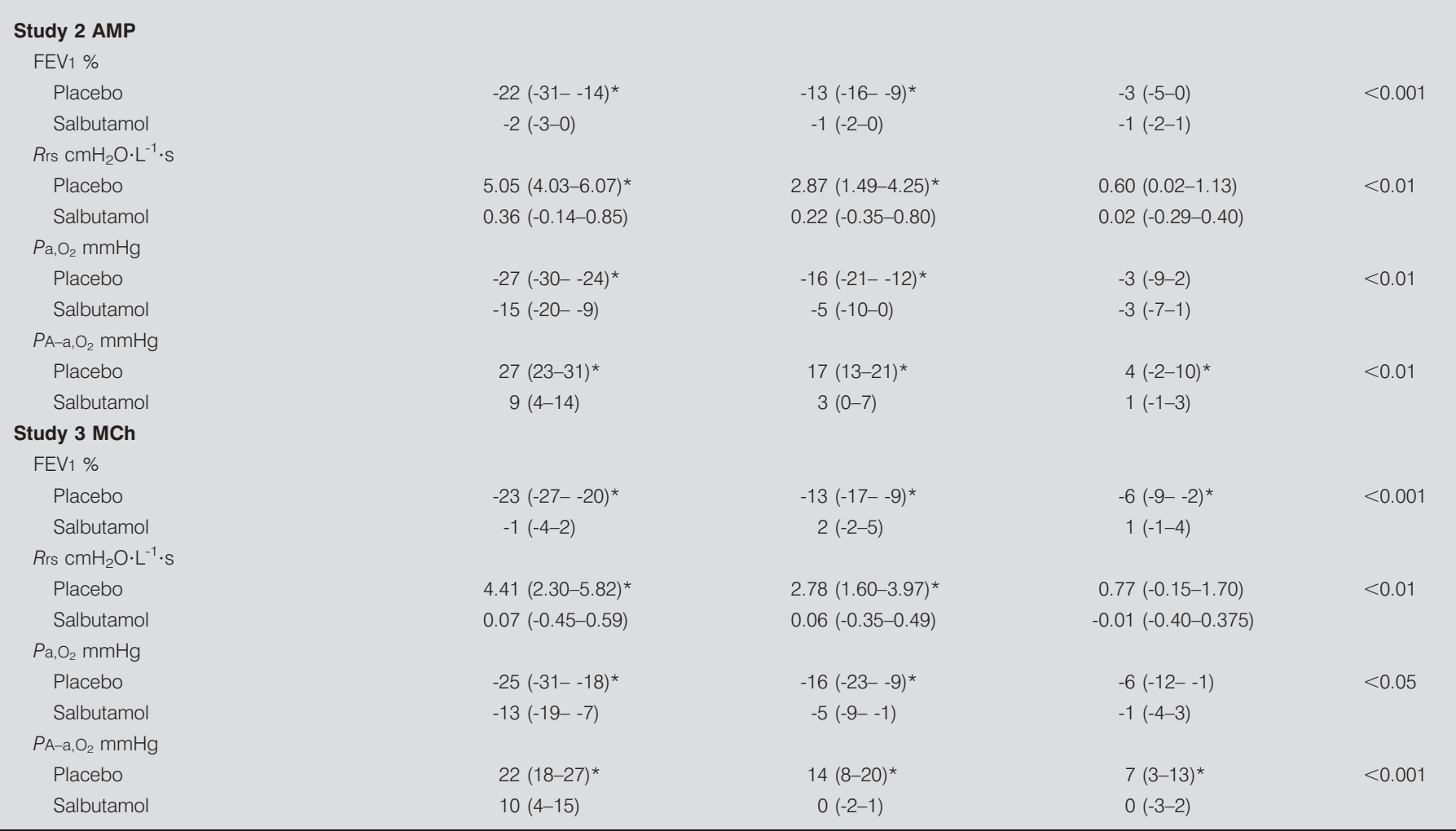

Data are presented as mean differences (95\% confidence interval) from baseline measurements, unless otherwise stated. FEV 1 : forced expiratory volume in one second

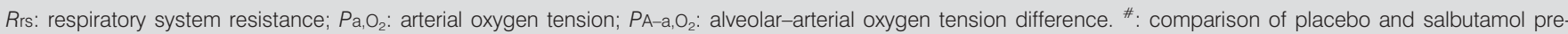
treated patients after AMP and MCh challenges, using ANOVA two-way repeated measures. *: $p<0.05$, for comparisons between placebo and salbutamol pre-treated patients at single time points. $1 \mathrm{mmHg}=0.133 \mathrm{kPa}$.

\section{Salbutamol effects}

Salbutamol exerted a complete bronchoprotective effect against $\mathrm{AMP}$ and $\mathrm{MCh}$ inhalation, but only partially inhibited pulmonary gas exchange disturbances. The present findings exhibited a less intense inhibitory effect than was observed after PAF [27] or $\mathrm{LTD}_{4}$ [7] in asthmatics pre-treated with salbutamol, in whom a similar dosage of salbutamol fully inhibited PAF- and $\mathrm{LTD}_{4}$-induced increased systemic and serum cellular abnormalities. It is possible that the latter effects could be related to an inhibition of endothelial venoconstriction in the airway microcirculation and the subsequent release of mediators that induce abnormal vascular permeability, a mechanism that can also be invoked to explain the inhibition of AMP-induced neutrophilia. Airway mucosal blood flow is increased in stable asthma compared with normal individuals, and does not increase following a standard dose of salbutamol [28]. The intriguing finding in the present study is that a complete post-salbutamol inhibition of gas exchange abnormalities, akin to the full inhibitory cellular response, was expected. The finding of residual mild gas exchange abnormalities after salbutamol pre-treatment, in the absence of evident bronchoconstriction, indicates some persistent $V^{\prime} / Q^{\prime}$ imbalance in peripheral lung regions. This $V^{\prime} / Q^{\prime}$ mismatching may be caused by $\beta_{2}$-agonist-induced pulmonary vasodilation, or persistent small airway narrowing where bronchodilators are less influential. It is likely that the latter two mechanisms may coexist, considering the degree of residual arterial hypoxaemia after salbutamol, during AMP and MCh challenges. Notwithstanding this, the potentially favoured central deposition of salbutamol [29], coupled with the contention that small airway inflammation is more significant, in that smaller airways have a greater likelihood of becoming obstructed than larger airways, due to the proportionally thicker inflamed epithelium and/or mucus layer, cannot be neglected.

\section{Conclusions}

The findings of the present study indicate that adenosine $5^{\prime}$ monophosphate and methacholine provoke similar gas exchange abnormalities during intense bronchoconstriction. However, at variance with methacholine, adenosine $5^{\prime}$-monophosphate induces a late sputum neutrophilic response. These findings suggest, first, that both bronchoconstrictive agents 
share a common mechanism of airway narrowing and, secondly, that the initial pathways differentiating their direct or indirect effects may overlap if severe bronchoconstriction is reached. Salbutamol caused complete inhibition of adenosine 5'-monophosphate-induced bronchoconstriction and sputum neutrophilia but only a partial blockade of gas exchange abnormalities, indicating that short-acting $\beta_{2}$-agonists may induce pulmonary vasodilation possibly associated with incomplete reversion of small airway dysfunction.

\section{ACKNOWLEDGEMENTS}

The authors would like to thank C. Gistau, F. Burgos and J.L. Valera for their outstanding technical support, and E. Polverino for her collaboration (all at Servei de Pneumologia, Hospital Clínic, Barcelona, Spain).

\section{REFERENCES}

1 Spicuzza L, Di Maria G, Polosa R. Adenosine in the airways: implications and applications. Eur J Pharmacol 2006; 533: 77-88.

2 Anderson SD, Brannan JD. Methods for "indirect" challenge tests including exercise, eucapnic voluntary hyperpnea, and hypertonic aerosols. Clin Rev Allergy Immunol 2003; 24: 27-54.

3 van den Berge M, Meijer RJ, Kerstjens HA, et al. PC(20) adenosine $5^{\prime}$-monophosphate is more closely associated with airway inflammation in asthma than PC(20) methacholine. Am J Respir Crit Care Med 2001; 163: 1546-1550.

4 van den Berge M, Kerstjens HA, Meijer RJ, et al. Corticosteroid-induced improvement in the PC20 of adenosine monophosphate is more closely associated with reduction in airway inflammation than improvement in the PC20 of methacholine. Am J Respir Crit Care Med 2001; 164: 1127-1132.

5 Rodríguez-Roisin R, Roca J. Contributions of multiple inert gas elimination technique to pulmonary medicine. 3. Bronchial asthma. Thorax 1994; 49: 1027-1033.

6 Wagner PD, Hedenstierna G, Rodríguez-Roisin R. Gas exchange, expiratory flow obstruction and the clinical spectrum of asthma. Eur Respir J 1996; 9: 1278-1282.

7 Casas A, Gómez FP, Dahlen B, et al. Salbutamol but not ipratropium fully abolish leukotriene $\mathrm{D}_{4}$-induced bronchoconstriction and gas exchange abnormalities in asthma. Am J Respir Crit Care Med 2003; 167: A142.

8 Masclans JR, Barberà JA, MacNee W, et al. Salbutamol reduces pulmonary neutrophil sequestration of platelet-activating factor in humans. Am J Respir Crit Care Med 1996; 154: 529-532.

9 Roca J, Félez MA, Chung KF, et al. Salbutamol inhibits pulmonary effects of platelet activating factor in man. Am J Respir Crit Care Med 1995; 151: 1740-1744.

10 McDonald DM. Neurogenic inflammation in the respiratory tract: actions of sensory nerve mediators on blood vessels and epithelium of the airway mucosa. Am Rev Respir Dis 1987; 136: S65-S72.

11 Roca J, Wagner PD. Contribution of multiple inert gas elimination technique to pulmonary medicine. 1. Principles and information content of the multiple inert gas elimination technique. Thorax 1994; 49: 815-824.

12 Gabrijelcic J, Acuña A, Profita M, et al. Neutrophil airway influx by platelet-activating factor in asthma: role of adhesion molecules and $\mathrm{LTB}_{4}$ expression. Eur Respir J 2003; 22: 290-297.
13 Cardús J, Burgos F, Díaz O, et al. Increase in pulmonary ventilation-perfusion inequality with age in healthy individuals. Am J Respir Crit Care Med 1997; 156: 648-653.

14 Gale GE, Torre-Bueno JR, Moon RE, Saltzman HA, Wagner PD. Ventilation-perfusion inequality in normal humans during exercise at sea level and simulated altitude. J Appl Physiol 1985; 58: 978-988.

15 Tabrizchi R, Bedi S. Pharmacology of adenosine receptors in the vasculature. Pharmacol Ther 2001; 91: 133-147.

16 Lagerstrand L, Larsson K, Ihre E, Zetterström O, Hedenstierna G. Pulmonary gas exchange response following allergen challenge in patients with allergic asthma. Eur Respir J 1992; 5: 1176-1183.

17 Echazarreta AL, Gómez FP, Ribas J, et al. Pulmonary gas exchange responses to histamine and methacholine challenges in mild asthma. Eur Respir J 2001; 17: 609-614.

18 Echazarreta AL, Dahlén B, García G, et al. Pulmonary gas exchange and sputum cellular responses to inhaled leukotriene $\mathrm{D}_{4}$ in asthma. Am J Respir Crit Care Med 2001; 164: 202-206.

19 Félez MA, Roca J, Barberà JA, et al. Inhaled plateletactivating factor worsens gas exchange in mild asthma. Am J Respir Crit Care Med 1994; 150: 369-373.

20 Muñoz PA, Manrique HA, Drakulovic MB, et al. Pulmonary gas exchange response to exercise and mannitol challenges in exercise-induced asthma patients. Proc Am Thorac Soc 2006; 3: A721.

21 Wiester MJ, Costa DL, Tepper JS, Winsett DW, Slade R. Agonist-mediated airway challenge: cardiopulmonary interactions modulate gas exchange and recovery. Respir Physiol Neurobiol 2005; 145: 183-199.

22 van den Berge M, Kerstjens HA, de Reus DM, Koëter GH, Kauffman HF, Postma DS. Provocation with adenosine 5'monophosphate, but not methacholine, induces sputum eosinophilia. Clin Exp Allergy 2004; 34: 71-76.

23 van den Berge M, Kerstjens HA, Postma DS. Provocation with adenosine $5^{\prime}$-monophosphate as a marker of inflammation in asthma, allergic rhinitis and chronic obstructive pulmonary disease. Clin Exp Allergy 2002; 32: 824-830.

24 Gibson PG, Simpson JL, Saltos N. Heterogeneity of airway inflammation in persistent asthma: evidence of neutrophilic inflammation and increased sputum interleukin-8. Chest 2001; 119: 1329-1336.

25 Fan M, Jamal Mustafa S. Role of adenosine in airway inflammation in an allergic mouse model of asthma. Int Immunopharmacol 2006; 6: 36-45.

26 van den Berge M, Polosa R, Kerstjens HA, Postma DS. The role of endogenous and exogenous AMP in asthma and chronic obstructive pulmonary disease. J Allergy Clin Immunol 2004; 114: 737-746.

27 Díaz O, Barberà JA, Marrades R, Chung KF, Roca J, Rodríguez-Roisin R. Inhibition of PAF-induced gas exchange defects by $\beta$-adrenergic agonists in mild asthma is not due to bronchodilation. Am J Respir Crit Care Med 1997; 156: 17-22.

28 Kumar SD, Emery MJ, Atkins ND, Danta I, Wanner A. Airway mucosal blood flow in bronchial asthma. Am J Respir Crit Care Med 1998; 158: 153-156.

29 Melchor R, Biddiscombe MF, Mak VH, Short MD, Spiro SG. Lung deposition patterns of directly labelled salbutamol in normal subjects and in patients with reversible airflow obstruction. Thorax 1993; 48: 506-511. 